\title{
Uma análise sobre a construção de conhecimentos por meio do desenvolvimento de protótipos.
}

\author{
PEREIRA, Clarissa; Mestranda; UNISINOS. \\ pereira.g.clarissa@gmail.com \\ FONTANELLA, Luiza; Mestranda; UNISINOS. \\ lu.fontanella@hotmail.com \\ MEYER, Guilherme; Doutor; UNISINOS. \\ gcmeyer@unisinos.br \\ NASCIMENTO, Manoela; Mestranda; UNISINOS. \\ mfreitasn@gmail.com
}

Palavras-Chave: Research through design, construção de conhecimentos, protótipos.

Resumo: O panorama contemporâneo referente aos estudos no campo do design aponta que a pesquisa por meio deste domínio é capaz de gerar aprendizados relacionados aos processos projetuais. Este artigo propõe estabelecer uma reflexão a respeito da construção de conhecimentos através da prática projetual e para tanto aborda o recente conceito de Research Through Design e a sua relação com o desenvolvimento de protótipos. Para colaborar com o estudo, é apresentado um projeto desenvolvido na Disciplina de Experimentação em Design de um Curso de Pós Graduação em Design, no intuito de exemplificar o tema e ressaltar saberes revelados na realização do exercício. Desta reflexão podem surgir recursos conceituais que subsidiem a prática projetual e os avanços dos estudos sobre a Research Through Design.

\section{Introdução}

O Design é uma prática exploratória. Nesse sentido, suas atividades projetuais ultrapassam as fronteiras da busca pela solução de um determinado problema de projeto. A problemática inicial é somente o ponto de partida para a jornada investigativa encarada pelo projetista (CROSS, 2006). Do ângulo acadêmico, o design é uma disciplina que apresenta diferentes possibilidades de desenvolvimento e exploração, não só teórica e conceitual, como também prática e experimental. Sendo assim, por suas múltiplas capacidades e por ser um campo de pesquisa relativamente recente, pode-se dizer que a disciplina do design é composta não só por concepções definidas e bem formuladas, mas também por alguns conceitos variados que ainda se encontram em fase de consolidação.

Nos últimos anos, tem sido estudada a prática do design como uma abordagem legítima para criação de novos saberes. Tal pressuposto tem sido analisado e defendido, em especial pelo campo de pesquisa Human Computer Interaction - $\mathrm{HCl}$, o qual realiza essa investigação por intermédio da Research Through Design (RTD). A capacidade do design em gerar aprendizado já havia sido mencionada por Flusser (2013) sob um viés antropológico. O filósofo propõe que as fábricas do futuro deverão ser semelhantes à laboratórios de aprendizagem, onde o homem terá acesso à informação, aprenderá, produzirá e compartilhará o seu conhecimento. Dessa forma, a Fábrica do Futuro será o modelo mais compatível às habilidades do homem, pois será capaz de potencializar suas capacidades criativas e intelectuais, sendo o design um ativo de alto potencial para a difusão desse novo formato. 
Ao analisar o emprego de metodologias e processos da prática do design como um legítimo método investigativo, o $\mathrm{HCl}$ vai além do foco da usabilidade, aproximando-se dos problemas considerados como "Wicked Problems" ou "Ill-defined Problems". Estes problemas são caracterizados por levarem em consideração elementos desconhecidos em seu contexto, trazendo ao ponto central incertezas e indefinições. Ou seja, tratam de questões que não podem ser solucionadas de forma simples e direta, por meio de processos pré-estabelecidos.

A pesquisa através do design ocupa-se em solucionar problemas por meio de uma abordagem holística, articulando o conhecimento e a teoria de forma simultânea e interativa com o processo projetual, tendo a intenção de reenquandrar a situação problemática a uma situação desejada (ZIMMERMAN et al, 2010).

Tendo em vista que a pesquisa através do design é um campo recente de estudo no meio acadêmico, seus conceitos são diversos e empregados em diferentes circunstâncias. Para Gaver (2012), a diversidade de abordagens em Research Through Design não deve ser encarada como um sinal de padrões inadequados ou falta de progresso, mas sim como algo natural de uma disciplina em desenvolvimento.

No entanto, tem crescido uma corrente, da própria comunidade do design, que vem questionando sobre a natureza e os padrões da pesquisa através do design. As discussões levantadas giram em torno do desejo de integrar métodos de pesquisa de design à outros instrumentos investigativos e resultados passíveis de validação, com o objetivo de consolidar conhecimentos e estruturar critérios para estudos realizados sob essa perspectiva (GAVER, 2012).

A Research Through Design é um modo investigativo que mantém suas bases de pesquisa atreladas à atividade prática projetual. Mesmo que se conheça elementos que legitimam esse tipo de pesquisa, sabe-se muito pouco em como operacionalizá-la a fim de construir novos conhecimentos através da ação projetual. Este artigo visa construir uma reflexão teórica a respeito da geração de conhecimentos durante o processo de projeto do design, abordando o conceito de Research Through Design.

\section{Geração de Conhecimento em Design}

O conhecimento é espinha dorsal do desenvolvimento da sociedade e das organizações contemporâneas. Dessa forma, a geração do conhecimento torna-se objeto de pesquisa emergente e valorizado, principalmente, por estar relacionado à capacidade de criação de soluções inovadoras.

Michel Polany (1966), autor do clássico estudo sobre conhecimento tácito, expõe sua concepção sobre o conhecimento como uma atividade na qual se integraliza o processo do saber. Na esteira desta temática, Maturana e Varella (2001) reforçam que o processo de busca e aquisição do conhecimento é constante, estando, necessariamente, ligado a uma ação de fazer ou desenvolver algo. 
Entende-se assim, que a pesquisa torna-se uma atividade intencional de busca por conhecimento, através de um exame minucioso ou investigativo, a fim de encontrar o novo ou de comprovar hipóteses. Existem diferentes tipos de pesquisa como a pesquisa básica, que se preocupa em investigar princípios gerais de casos ou situações; a pesquisa aplicada, que ocupa-se em adaptar as descobertas da pesquisa básica à determinados tipos de problemas; e, a pesquisa clínica, que envolve os dois tipos citados, pois aplica as descobertas de ambas em determinadas situações. A pesquisa clínica também testa conhecimentos e elabora novas questões sobre o tema investigado (FRIEDMAN, 2003).

Segundo o autor, grande parte da prática do design tem caráter clínico, já que os designers necessitam entender os problemas de projeto para distinguir, através de seus conhecimentos teóricos e suas experiências práticas, tipos de problemas e possíveis soluções alternativas. Assim, a prática de projeto torna-se a base de geração de conhecimento no design.

Nesse contexto, compreende-se o design como um campo habituado à articular conhecimentos especializados que reúnem técnica, arte, experiência, observação, experimentação e criatividade. O seu processo de projeto contém a peculiaridade de traçar um caminho não linear, que diante de um problema a ser solucionado extrapola a simples sistematização de conhecimentos, provocando a combinação e a concepção de novos saberes (FRAGA, 2011).

Complementando, Meroni (2008) descreve a capacidade do design em habilitar indivíduos para a construção de novas ideias e novas percepções, criando uma plataforma de conhecimentos que as possibilitem operar em determinado contexto ou em uma questão específica. A autora comenta que este é um processo interpretativo, que tem como objetivo e esforço maior a tentativa de compreender determinada circunstância, de extrair dela novas informações e gerar efeito de sentido entre todos os envolvidos.

Nesta mesma lógica, o pedagogo americano Donald Schön (2000) introduz a visão do design como uma prática reflexiva, na qual novos saberes são desenvolvidos durante a ação projetual. Para o autor, os designers lidam com problemas com alto grau de complexidade, indefinição e incerteza. Na literatura contemporânea, tais problemas têm sido denominados como "Wicked Problems", "ill-defined", "undetermined", dentre outros.

A insegurança presente nestas situações é chamada por Schön (2000) como "elemento surpresa", sendo o modo de operar este componente desconhecido por meio da reflexão na ação. O autor define reflexão na ação como o processo de gerar conhecimento enquanto se realiza algo, fazendo surgir novos saberes que influenciarão as ações subsequentes do profissional durante o projeto. Em outras palavras, é a reflexão do sujeito sobre a prática, durante a sua prática projetual, assumindo uma posição analítica do seu próprio conhecimento, bem como da questão problema. 
A reflexão na ação tem uma função crítica, questionando a estrutura de pressupostos conhecidos. Pensamos criticamente sobre o pensamento que nos levou a essa situação difícil ou essa oportunidade e podemos nesse processo reestruturar as estratégias de ação, as compreensões dos fenômenos ou as formas de conceber os problemas (pg. 33).

Desse modo, refletir sobre e durante a ação projetual pode ser compreendido como uma postura crítica que o designer assume, questionando a situação com a qual se depara. Os problemas são encarados como situações complexas e, na medida em que vão sendo resolvidos, fornecendo clareza ao projetista, gerando novos questionamentos sobre o tema e impulsionando uma reflexão crítica, para além das metodologias disponíveis.

Mesmo que os processos executados durante o projeto não sigam uma trajetória linear, ações racionais e reflexivas são intercaladas, hora em ações bem definidas, hora em hipóteses pouco prováveis. Conforme as etapas vão sendo realizadas, novas informações agregam às questões iniciais, gerando novos conhecimentos, bem como reorientação dos processos de projeto, em função da identificação de novas possibilidades para a solução do problema original. Assim, o ato de projetar pode ser associado à processos de aprendizagem e geração de conhecimentos.

Tais características do modo pelo qual processa o design, distanciam-se dos procedimentos pragmáticos da ciência tradicional, entendida nos moldes da taxonomia proposta por Friedman (2003). As qualidades do processo de design descritas a partir de Schön, pensadas à luz da construção de conhecimento, vêm se revelando pertinentes para pensar problemas complexos como os que se postam na sociedade contemporânea. Procuraremos posicionar tal discussão em meio ao problema da pesquisa através do design, ou Research Through Design.

\section{Research Through Design}

A abordagem do design como ciência, sendo uma prática projetual capaz de gerar novas teorias, tem sido tema de discussão adotado por profissionais e pesquisadores do meio acadêmico. Nigel Cross (2006) levanta este debate, trazendo uma perspectiva histórica do design, que versa desde o princípio racional e objetivo (SIMON, 1981), até alcançar o que o autor denomina de Design Ways Of Knowing. Para ele, o design não deve ser classificado como ciência exata ou social, pois tal disciplina tem suas particularidades próprias do saber, capazes de gerar conhecimento.

O termo Design Ways of Knowing - a maneira design de raciocinar - faz referência à ideia de que o design tem "coisas a saber", um "jeito próprio de saber" e caminhos específicos para "encontrar esse saber". De acordo com Cross (2004), o design é um campo que contempla na sua prática projetual uma cultura própria de desenvolver processos e gerar conhecimentos. Assim, o autor desdobra o Design Ways of Knowing em cinco dimensões (Figura 1): 


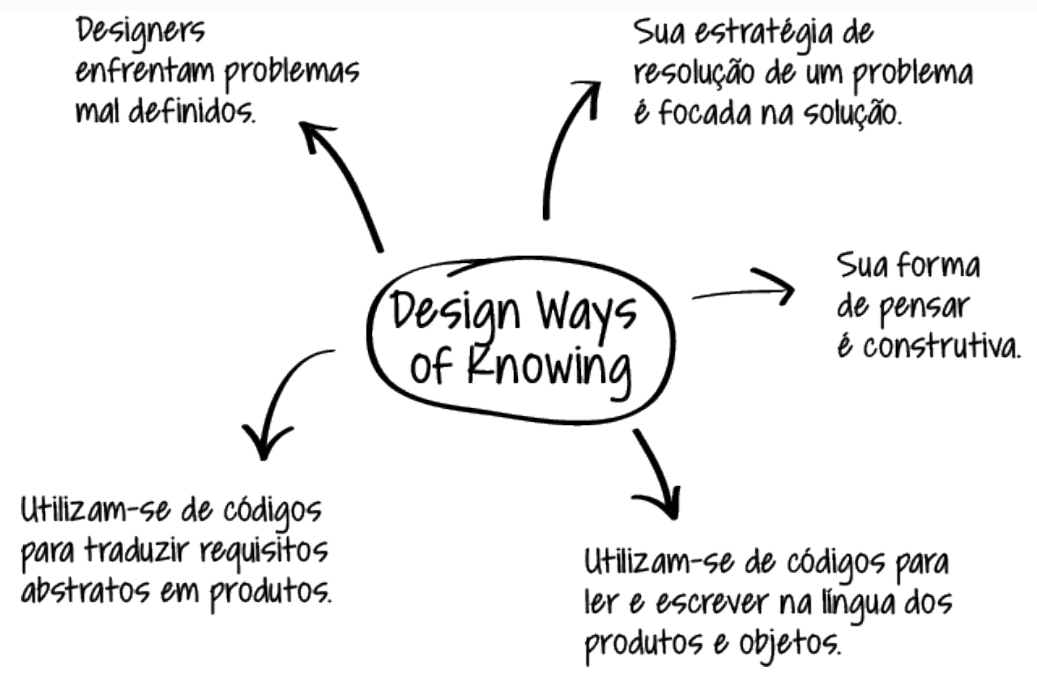

Figura 1 - As dimensões do Design Ways of Knowing. Fonte: Cross (2011)

A dimensão referente ao pensamento construtivo do designer destaca a criação de novos saberes a partir da ação projetual. Com base em estudos desenvolvidos a respeito das habilidades e capacidades do design, observa-se a possível aproximação da ciência, do design e da prática projetual por meio de pesquisas realizadas através do design, conceituadas como Research Through Design.

O conceito de pesquisa através do design vem sendo bastante empregado não só na esfera acadêmica, bem como na linguagem coloquial. Em ambas as áreas o sentido é o mesmo: o design compreendido como uma atividade geradora de conhecimento (KOSKINEN et. al., 2012).

Apoiado em estudos desenvolvidos na Royal College of Art, o termo foi definido por Christopher Frayling (1993) que, ao segmentar em categorias a pesquisa em design, através do design e para o design, difundiu e popularizou o conceito. De acordo com o autor, a pesquisa através do design significa tratar o design como uma forma específica de raciocinar e adquirir conhecimento. Tais habilidades contribuem para a compreensão de circunstâncias e elementos que existem para além do design. Ou seja, refere-se a uma ação investigativa ativa (JONAS, 2015). Dessa forma, essa técnica de pesquisa produz teoria de maneira distinta da científica, sendo uma teoria de ação seguida por um significado, ao invés de sentido seguido de ação (ZIMMERMAN et al, 2010).

Em concordância, Alain Findeli (2001) percebe a investigação através do design como uma pesquisa aplicada, voltada à prática de projetos complexos, construídos por meio de pesquisa e desenvolvimento. Para o autor, a Research Through Design caracteriza-se por um processo genuíno do design de geração de conhecimento, onde os participantes criam conexões e passam a propor efeito de sentido à gama de informações que compõem o processo investigativo. Ainda, pode ser compreendida como um processo de design, no qual o conhecimento é ampliado em tempo real, dando início a um ciclo de aprendizagem interativa de planejar, agir, observar e refletir. 
Zimmermann et al (2010), avançam os estudos sobre RtD buscando identificar em que circunstâncias a pesquisa através do design pode se tornar últil, bem como podem ser estruturadas diretrizes, protocolos e instrumentos investigativos para a operacionalização deste método. Tais questões tornam-se fundamentais para a formalização de qualquer disciplina como um método de pesquisa.

Nesse contexto, o $\mathrm{HCl}$ aponta que o objetivos de suas pesquisas é justamente expandir e formalizar o uso da pesquisa através do design como um método de estudo. Todavia, ainda que a Research Through Design seja um termo que está se tornando comum na comunidade acadêmica, seus princípios ainda não estão definidos.

Percebe-se alguns obstáculos que dificultam a legitimação da RtD como método, além de não existir critérios científicos definidos para as abordagens e validação das contribuições obtidas através dessa prática. Acredita-se que estas dificuldades ocorrem pelo fato de ser um processo que tem como objetivo inicial o foco em desenvolvimento de produtos, serviços ou sistemas e não na geração de novos saberes. Dessa forma, o conhecimento adquirido pode permanecer tácito com o projetista, não sendo externalizado e explicitado para outros grupos ou disciplinas. Sendo assim, não se tem padronizado nenhuma forma de registro para documentar o conhecimento que surge através e durante a prática deste tipo de pesquisa (ZIMMERMAN et al, 2010).

De acordo com os autores, para que isso seja possível, é necessário estimular as seguintes iniciativas: (a) o desenvolvimento de metodologias, (b) obter mais exemplos de investigações, (c) possuir mais críticas referente às teorias e (d) estabelecer critérios de avaliações. Assim, uma forma de consolidar o desenvolvimento de metodologias é por meio da documentação do processo de projeto, sendo possível identificar como teorias de outras disciplinas podem contribuir para este fim.

Estimular a proliferação da divulgação de exemplos de pesquisas realizadas através do design, permite que o conhecimento gerado ao projetista não se limite apenas à ele, além de tornar-se uma forma de embasar e fomentar a pesquisa através do design. Considerando sua natureza, este é um meio investigativo que não se desenvolve, somente, pelo aumento de senso comum, mas também pelo debate e colaboração entre a comunidade do design e outras disciplinas.

Assim, apresentaremos um projeto desenvolvido em uma disciplina de Experimentação em Design, a fim de colaborar e exemplificar os conceitos e a reflexão sobre o tema.

\section{Método}

A partir da revisão de literatura sobre geração de conhecimento em design e Research Trough Design, será relatado uma experiência projetual ocorrida entre março e abril de 2016. As atividades foram propostas em uma disciplina de Experimentação em Design, para alunos de um curso de mestrado em design. As tarefas foram desenvolvidas em sala de aula, ocupando 8 horas semanais, durante cinco se- 
manas, somando um total de 40 horas. Antes de iniciar a atividade projetual, os projetistas participaram de uma discussão sobre a construção de conhecimento por meio de projeto. A partir dessa discussão, os alunos foram orientados a se deterem em momentos específicos de críticas sobre os estágios de projeto. As seções de crítica foram feitas ao término de cada semana. Neste artigo, apresentaremos o olhar de uma das 5 equipes que participaram da atividade. A equipe era composta por 3 estudantes (dois deles com formação em design e um com formação em produção audiovisual). O relato é orientado pelos relatórios críticos de projeto.

Assim, iremos descrever as minúcias do processo, pontuando os momentos em que as descobertas foram reveladas pelo grupo.

\section{Resultados e Discussões}

\section{Projeto de Protótipo}

O projeto elaborado pelo grupo teve como tarefa principal encontrar, através da prática do design, uma forma de reduzir a elevada taxa de $84,6 \%$ de partos realizados por meio de cesária no Brasil. Assim, o briefing trazia a seguinte questão problema: "Como reduzir essa indesejável estatística oferecendo condições mais desejáveis para mães e bebês durante o parto? Que tipo de artefatos, ações ou sistemas podem ser propostos para atender as recomendações da Organização Mundial da Saúde (OMS)? Ou, de forma geral, como o design pode auxiliar nesse contexto desequilibrado?".

Desse modo, o grupo tendo o primeiro contato com o briefing começou a debater sobre as informações fornecidas e a questão problema de modo geral. Observou-se que as duas designers do grupo tinham a tendência de analisar criticamente, bem como questionar os dados concedidos. Percebe-se, nessa ação, o início de um processo de afastamento do problema, onde passaram a vê-lo "de cima", ampliando seu escopo e considerando um contexto maior do que o inicial. Assim, começaram a ser considerados para o projeto os fatores influenciadores, limitantes, todos atores envolvidos no procedimento de parto e o período de gestação da mãe, como também, demais elementos que poderiam ser verificados futuramente.

A participante do grupo que atua em outra área (não designer), no primeiro momento, colocou-se na posição de gestante, criando empatia com público apontado pelo briefing. Dessa forma, a aluna assumiu uma posição perante o problema que poderia influenciar suas futuras decisões durante a ação projetual.

Passada a fase inicial, de interpretação do briefing, levantamento de dados e análise do contexto hospitalar e do universo das gestantes, bem como de todos os atores envolvidos no período de gestação e parto, o grupo identificou a oportunidade de trabalhar uma possível solução com a seguinte questão: "Como reduzir o tempo de trabalho de parto dentro dos hospitais?". Com essa problemática, as alunas 
estariam contemplando um número considerável de atores envolvidos em um procedimento de parto (gestantes, bebês, parceiros (as), rede hospitalar, plano de saúde, familiares e doulas). Deu-se seguimento, então, a etapa de construção de cenários (Figura 2).

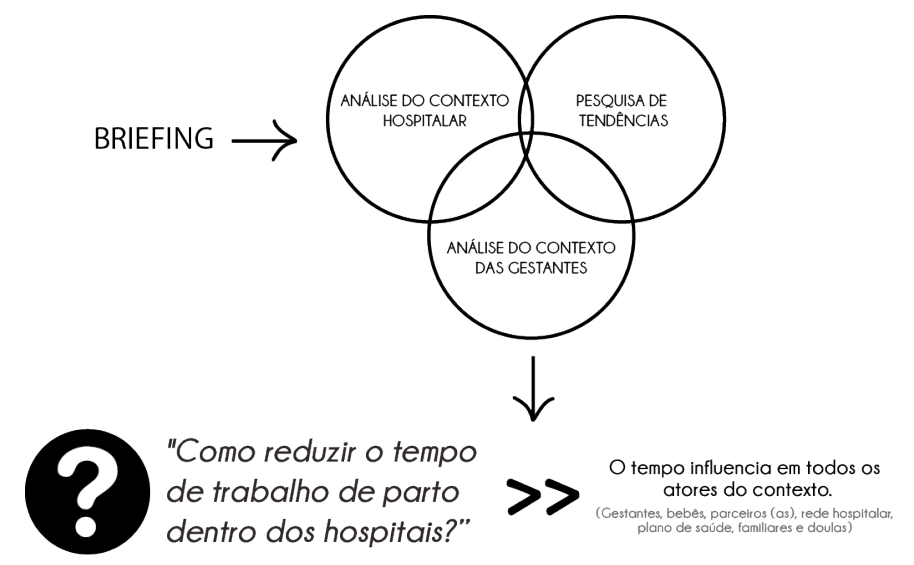

Figura 2 - Síntese da fase inicial do projeto e identificação do problema.

Primeiramente, foram debatidas as possíveis polaridades que se adequariam a este panorama, ficando definidas como: Sociedade Ativa x Sociedade Passiva; Ambiente Contemporâneo x Ambiente Tradicional. Logo, o grupo iniciou o processo de elaboração das visions de cada cenário, sendo esta fase um momento de bastante conversação e troca de perspectivas entre a equipe, que elegeu trabalhar com o cenário figurado por uma sociedade ativa inserida em um ambiente contemporâneo. Observou-se que a cenarística se apresentou como um instrumento no qual o grupo conseguiu obter clareza sobre possíveis atributos que contemplariam a solução projetada, e não como comumente utilizado, um norteador que orienta a escolha da solução desejada. A Figura 3 representa o cenário elegido pela equipe, bem como alguns dos atributos listados para o quadrante a ser trabalhado.

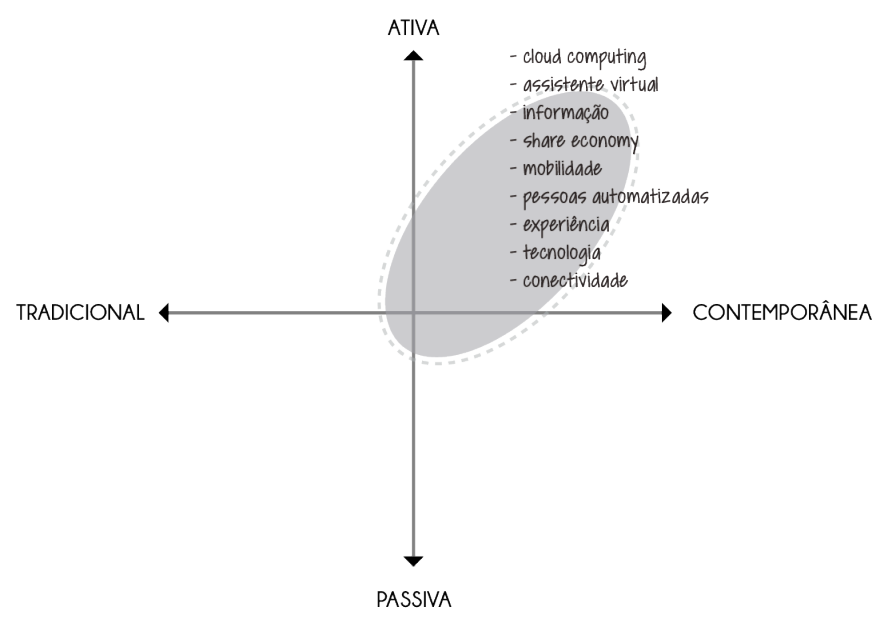

Figura 3 - Cenário elegido pela equipe para o desenvolvimento do projeto.

Em seguida, o grupo iniciou a fase de prototipação do artefato. No design, entende-se a ação projetual como o caminho para transformar as ideias em realidade. Assim, a etapa de experimentação é um 
dos passos essenciais do processo de projeto, pois se torna o momento em que o designer desenvolve o protótipo de sua ideia, permitindo testar sua funcionalidade e aplicabilidade, para então aperfeiçoar a solução projetada. Como mencionado, durante os processos de projeto são articulados conhecimentos que reúnem técnica e arte, experiência e observação, experimentação e criatividade.

Assim, como solução para o problema de projeto o grupo projetou um sistema capaz de transmitir para a gestante informações durante todo o período de gestação, bem como sobre o procedimento de trabalho de parto. Tais informações englobariam temas como saúde, alimentação, exercício físico, entretenimento, tipos de parto, dentre outros. A gestante, ao entrar em trabalho de parto, receberia dicas do sistema para mantê-la calma e informada sobre o que fazer até o momento de se dirigir ao hospital. A Figura 4 ilustra o protótipo desenvolvido pelo grupo:

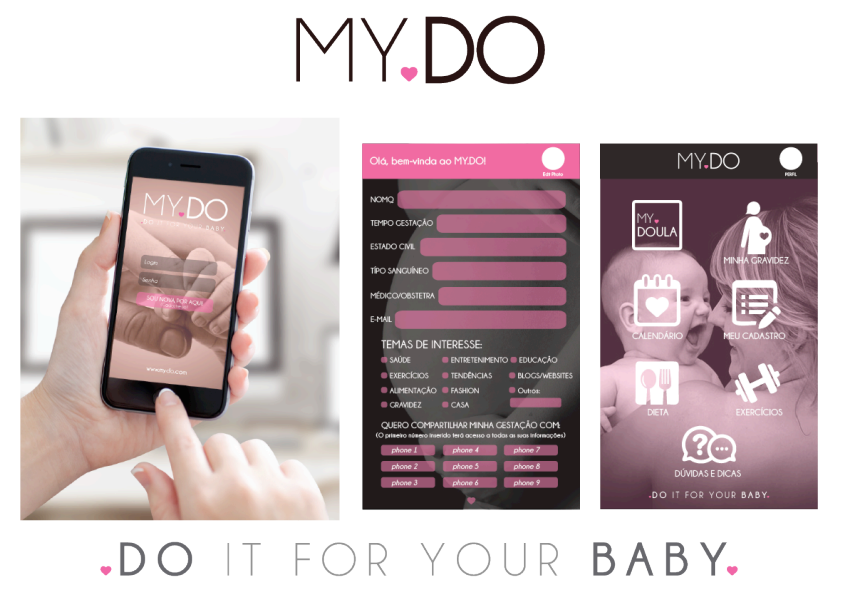

Figura 4 - Protótipo desenvolvido pelo grupo: Aplicativo My.Do.

Nesse sistema, a rede hospitalar se beneficiaria ao alimentar seus bancos de dados com informações sobre as gestantes, além de otimizar a logística de seu pessoal e seus procedimentos do setor de maternidade. As empresas fornecedoras de assistência médica, diminuiriam seus custos devido à redução do tempo de seus usuários na utilização da infraestrutura hospitalar. Considerando o grande número de pesquisas que comprovam a importância do bebê em permanecer o maior tempo possível no útero da mãe, a fim de receber todos os nutrientes necessários, o sistema contribuiria nesse sentido. A permanência do bebê em trabalho de parto está muito associado a presença da Doula, que é outro ator beneficiado com o sistema, já que o acompanhamento da Doula é fundamental para manter a gestante tranquila e segura até o momento de se encaminhar ao hospital e iniciar o trabalho de parto. 


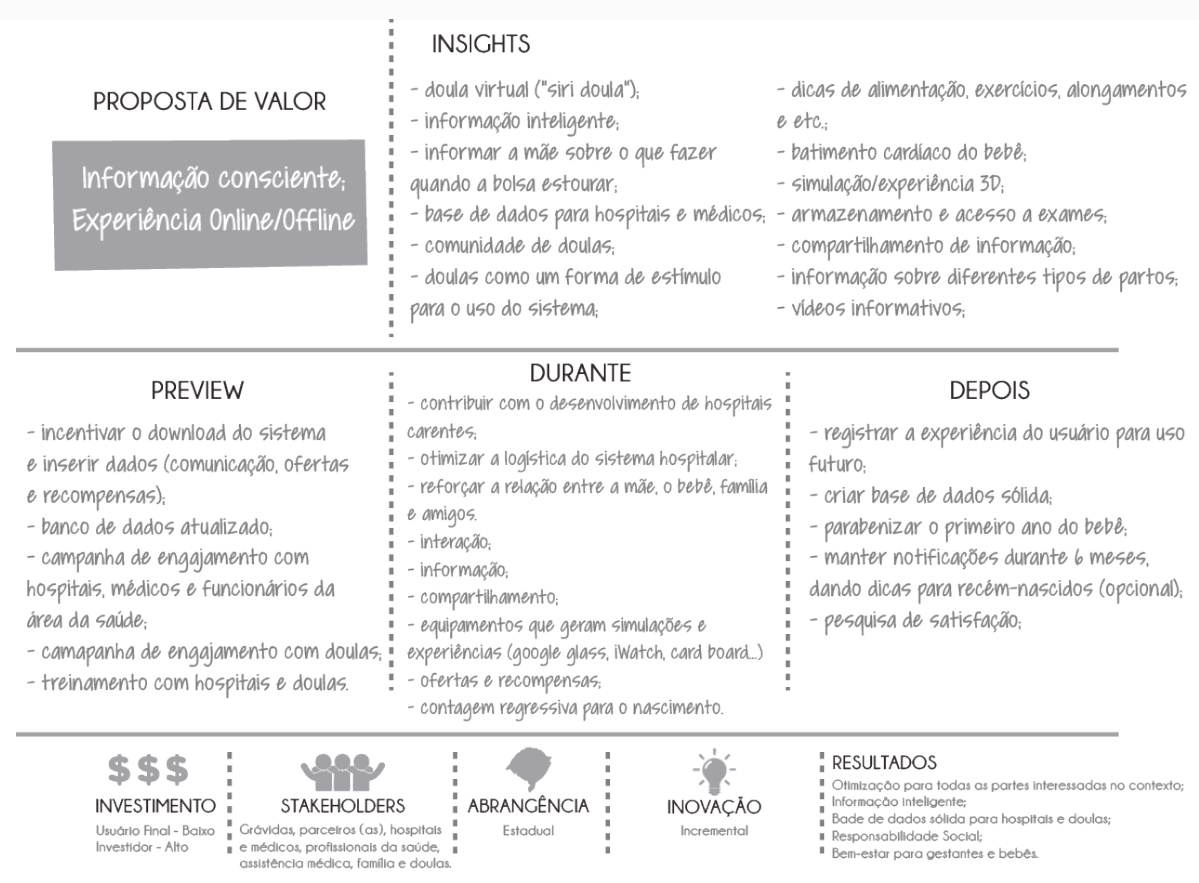

Figura 5 - Síntese da análise do protótipo proposto pela equipe.

Observa-se que a proposta sugerida pela equipe, engloba variadas questões que vão além do problema de projeto inicial. Assim, ao logo da prática projetual a questão norteadora da atividade é ampliada, gerando um novo problema de projeto relacionado à conscientização da informação.

A seguir, descrevemos as descobertas reveladas pelas estudantes durante a atividade realizada para a disciplina do curso.

\section{ências.}

\section{O processo de empatia do designer influenciado por suas bagagens e experi-}

O grupo ao ter o primeiro contato com o briefing da atividade apresentou diferentes comportamentos de seus integrantes. A participante do grupo que não tem formação em design colocou-se na posição de gestante, criando empatia com público apontado pelo briefing. Já as outras duas integrantes, designers, conseguiram analisar e questionar os dados concedidos, se afastando do problema e considerando um contexto mais amplo que o delimitado inicialmente.

Nesse momento, pôde-se refletir sobre como os designers e os não designers trabalham em contextos considerados desconhecidos e como gerenciam posicionamentos que possam influenciar o projeto, por meio de sua bagagem de conhecimentos e experiências.

A iniciativa de primeiramente questionar e afastar-se do problema, para interpretá-lo sob uma perspectiva mais dilatada, possivelmente, representa como o designer lida diariamente com os seus projetos. Dessa forma, acredita-se ser equivocada a ideia de que o designer não é influenciado por sua bagagem 
de especialidades e vivências. Contudo, a influência que a sua experiência e o seu conhecimento provoca no projeto se dá de forma divergente de outras áreas.

Nesse contexto, Cross (2004) afirma que o conhecimento especializado do design não é, somente, questão de talento. Ao diferenciar designers iniciantes de experientes, o autor comenta que parte do desenvolvimento das especificidades do designer encontra-se na acumulação de experiência. A exposição a um determinado problema de design gera a habilidade mental de retroceder aos exemplos vividos e a formar novas conceituações abstratas.

Complementando, Kahneman (2003), considera que o designer ao se encontrar diante de situações incertas e sem informações suficientes, faz uso de sua intuição para definir caminhos para o projeto. Segundo o autor, a intuição acontece através de processos cognitivos denominados como processos heurísticos, que utilizam atalhos que auxiliam a tomada de decisão. Assim as heurísticas baseiam-se na representatividade, como a similaridade de situações, e na disponibilidade, através de experiências, memórias e imaginação.

Observa-se assim, que o designer possui uma característica própria que é a sua natureza exploratória. Nesse sentido, diante de um problema específico é capaz de lidar com o conhecimento e a informação contemplando o todo, sem ignorar possíveis elementos que não são do seu entendimento. Diante das incertezas do brefing o designer busca alargar seus conhecimentos sobre o tema e evoluir na compreensão do problema sem propor respostas simples e diretas.

\section{A construção de cenários como meio para definição de critérios e atributos para a solução projetada.}

Os cenários dirigidos pelo design buscam, por meio de construção de um mundo futuro, nortear as ações e decisões tomadas no presente, com o objetivo de alcançar futuros desejáveis (DESERTI, 2007; REYES, 2015). Assim, dentre as diferentes formas de projetar cenários, o design assume o meio de narrações de histórias sobre mundos possíveis.

Nesse sentido, Celaschi (2007) comenta que o cenário se torna uma plataforma de reflexão, compartilhamento e administração de horizontes. Um dos seus objetivos é arquitetar uma visão compartilhada, questionando antigos aprendizados e deslocando visões estabelecidas que desafiam o modelo mental vigente.

A prática tem uma característica crítica-questionadora que testa e provoca o pensamento estratégico, promovendo um ambiente de debate sobre determinadas questões. A projetação destes mundos oportuniza que indivíduos diferentes pensem coletivamente a respeito do amanhã. As discussões revelam variadas reflexões e a conjugação destas diferentes perspectivas gera, não somente, novos apren- 
dizados que ampliam o campo mental dos atores envolvidos, mas também viabiliza uma linguagem em comum entre os participantes.

Entende-se este recurso como um sistema de inteligência de apoio à decisão em situações em que predominam mudanças e incertezas, pois amplia a base de dados e expande as percepções e os modelos mentais, gerando aprendizagem entre os participantes (HEIDJEN, 2009).

Observa-se assim, que os cenários auxiliam os designers a administrar as incertezas do projeto. Ao pensarem em futuros possíveis, os projetistas escolhem sobre qual cenário desejam trabalhar, para então, criarem condições e imaginarem possíveis artefatos que façam sentido à cena escolhida. Contudo, para o grupo de estudantes, a construção de cenários serviu como um meio de identificar requisitos para uma possível solução do problema. No decorrer da atividade, a equipe pôde identificar esta questão a partir dos apontamentos trazidos para o cenário escolhido para o projeto, os quais traziam possíveis atributos e elementos para um artefato, e não para uma situação imaginada. Nota-se que a prática cenarística proporcionou novas perspectivas ao grupo, ampliando sua visão coletiva para potenciais atributos a uma solução sistêmica e não pontual.

\section{Reenquandramento da situação problemática.}

Segundo Simon (1981), a etapa de experimentação possui um papel fundamental no desenvolvimento do projeto, pois através da simulação em um ambiente seguro e controlável é possível prever acontecimentos. Sendo assim, a execução e o teste de protótipos tem o potencial de gerar resultados muitas vezes diferentes do esperado, pois o profissional ganha conhecimento de aspectos que não estavam previstos antes da prototipação da ideia.

Pôde-se perceber que as estudantes, ao desenvolver o protótipo deste artefato, evoluíram sua compreensão sobre o problema e depararam-se com um novo problema de projeto. A solução imaginada pelas alunas já não se relacionava com a questão do tempo nos hospitais, e sim com a conscientização da informação disponibilizada. Durante a ação projetual, as estudantes foram acumulando informações e ganhando conhecimentos sobre o contexto no qual o projeto estava inserido, podendo perceber diferentes elementos e variadas possibilidades. Ou seja, a co-evolução do problema fez o grupo alcançar uma nova questão para o projeto: "Como conscientizar a informação sobre a gestação e o procedimento de parto disponibilizada para a sociedade?'

Assim, percebe-se que a prática do design desperta no projetista descobertas reveladas durante sua ação, na medida em que o pensamento construtivo é estimulado e desenvolvido de acordo com o amadurecimento do projeto.

\section{Conclusões}


Considera-se que a Research Through Design tem potencial para se tornar um método investigativo, sendo sustentado pela atividade prática projetual e pela compreensão do design como uma área geradora de conhecimento. Apesar de já existirem elementos que reconheçam o design como disciplina científica, os estudos sobre o uso de projetos como modo de inquérito ainda são muito recentes, com poucos conceitos estabelecidos. Contudo, as peculiaridades da ação projetual, pensadas à luz da construção de conhecimento, têm se tornado relevantes para a busca por instrumentos e abordagens que possam contribuir para a validação da RtD como modo de geração de novos saberes no campo.

Este artigo procurou construir uma reflexão relacionada à geração de novas descobertas durante o processo de projeto de design, orientada pelo conceito de Research Through Design. Como forma de complementar os conceitos explorados, foi apresentado, como exemplo ilustrativo, um exercício realizado por uma turma de estudantes de design.

A partir da revisão teórica e da análise da atividade projetual, percebe-se que a prática do design desperta no projetista descobertas reveladas durante a sua ação. Mais precisamente, foi possível tocar algumas das evidências que surgiam em meio às dinâmicas projetuais, que apontavam para 3 tópicos passíveis de apreciação, a saber: (a) o processo de empatia do designer influenciado por suas bagagens e experiências; (b) a construção de cenários como meio para definição de critérios e atributos para a solução projetada; e, (c) reenquandramento da situação problemática. Tais questões devem ser pensadas como campos abertos que requerem crítica e investigação. Apesar da falta de clareza sobre os seus procedimentos de validação, não se deve aqui sugerir irrelevância, pois o aspecto contingente que lhes é característico não Ihes subtrai a pertinência. De qualquer forma, observa-se um campo a ser explorado, especialmente no que diz respeito a compreensão da natureza dos procedimentos de validação que tal mecanismo de descoberta requer.

Sobre a postura do designer, é possível dizer que conforme o designer posiciona-se criticamente diante da atividade projetual, assume uma propensão dada a novas descobertas que outros modos de operação menos críticos não conseguem alcançar. A crítica aqui deve ser entendida em parte pela sensibilização dos participantes em relação às possibilidade que a Research Through Design Ihes permitia.

Deve-se salientar que este artigo entende a Research Through Design como um modo distinto de inquérito, que afasta-se muitas vezes das maneiras científicas de validação. Os estudos sobre RtD são ainda incipientes e acompanhados da problemática da falta de registros analíticos e da divulgação de exemplos para críticas e futuras aplicações, causando dificuldades para avaliar a possibilidade de se pensar a prática como um método investigativo. 


\section{Referências}

CELASCHI, F. Dentro al progetto: appunti di merceologia contemporanea: In: CELASCHI, F.; DESERTI, A. Design e innovazione: strumenti e pratiche per la ricera applicada. Roma: Carocci Editore, 2007, p.15-38.

CROSS, N. Design Thinking: Undestanding how designers think and work. Berg: Nova lorque, 2011.

CROSS, N. Designerly ways of knowing. Springer: London, 2006.

CROSS, N. Expertise in design: an overview. Design Studies, [S.I.], v. 25, n.5, p. 427-441. Sept., 2004.

DESERTI, A. Intorno al progetto: concretizzare l'innovazione. In: CELASCHI, F.; DESERTI, A. Design e innovazione: strumenti e pratiche per la ricerca applicata. Roma: Carocci Editore, 2007, p. 57-61.

DURRANT A. C. el al. Developing a Dialogical Plataform for Disseminating Research Through Design. Constructivist Foundations, 11, 1, 8-21, Nov. 2015

FINDELI, A. Rethinking Design Education for the 21st Century: Theorical, Methodological, and Ethcical Discussion. Design Issues. 17, 1, 5-17, Abril, 2001

FLUSSER, V. O mundo codificado. Por uma Filosofia do design e da comunicação. $1^{\text {a }}$ ed. São Paulo: Cosac Naify, 2007.

FRAGA, Eliara. Workshops em design: espaços de aprendizagens e geração de conhecimentos. Dissertação (Mestrado) - Universidade do Vale do Rio dos Sinos - UNISINOS, Programa de PósGraduação em Design, 2011.

FRAYLLING, Christopher. Research in Art and Design. London: Royal College of Art, 1993.

FRIEDMAN, K. Theory Construction in design research: criteria, approaches, and methods. Design Studies, 24, 2003, (507-522).

GAVER, W. What should we wxpet from research through design? In:

SIGCHI Conference on humam factores in Computing Systems. ACM, New York, 2012, 937-946.

HEIJDEN, K. V. Planejamento de Cenários. Porto Alegre: Bookman, 2009.

JONAS, W. Research Through Design is more than just a new forma of disseminating design. Constructivist Foundations, 11, 1, 32-36, Nov. 2015

KAHNEMAN, D. Maps of bounded rationality: psychology for behaviral economics. The American Economic Review, v.93, n.5, p.1449-1475, 2003.

KOSKINEN, Ilpo et. al. Design Research Through Practice: From the lab, field and showroom. Waltham: Elsevier, 2012.

MATURANA, H. R., \& VARELLA, F. J. (2001). A árvore de conhecimento: as bases para a compreensão humana. São Paulo: Palas Athena.

MERONI, A. Strategic design: where are we now? Reflection around the foundations of a recent discipline. Strategic Design Research Journal, v. 1, n. 1, p. 31-38, 1 dez. 2008. 
POLANYI, M. The Tacit Dimension.London: Routledge and Kegan Paul, 1966.

REYES, P. Projeto por cenários: o território em foco. Porto Alegre: Sulina, 2015. 268p.

SCHÖN, D. Educando o profissional reflexivo: um novo design para o ensino e a aprendizagem. Porto Alegre: Artmed Editora, 2000.

SIMON, Herbert A.; As ciências do articial / The Sciences of the artificials. M.I.T, 1981.

ZIMMERMANN, J. STOLTERMAN, E. FORLIZZI, J. An Analysis and Critique of Research through

Design: towards a formalization of research approach. Denmark, 2010. 